\title{
Increased plasma cyclic nucleotide concentrations in congestive heart failure
}

\author{
K OGAWA, H SHIOZU, K MIZUNO, M BAN, T ITO, T SATAKE \\ From the Second Department of Internal Medicine, Nagoya University School of Medicine, Nagoya, Fapan
}

SUMMARY Plasma concentrations of cyclic nucleotides (adenosine monophosphate (AMP) and guanosine monophosphate (GMP) were measured by an ultrasensitive radioimmunoassay in 138 patients with heart failure due to various causes. Measurements were related to the New York Heart Association classification of symptoms, plasma noradrenaline concentrations, and mean pulmonary artery pressures. Serial concentrations of cyclic AMP and GMP were also measured daily in four patients treated for acute left ventricular failure. Plasma concentrations of cycle AMP were related to the severity of the heart failure, plasma noradrenaline concentrations, and pulmonary artery pressures. Cyclic AMP concentrations fell rapidly after treatment of acute left ventricular failure. Plasma concentrations of cyclic GMP also depended on the severity of heart failure and the pulmonary artery pressure, and decreased sharply with treatment although remaining at a high value. The cyclic GMP concentrations were significantly higher in patients with mitral stenosis than in those with other types of heart failure.

It is well known that sympathetic nervous activity increases in patients with congestive heart failure. Chidsey et al reported that urinary excretion of noradrenaline was increased in heart failure. ${ }^{1}$ Studies by Thomas and Marks ${ }^{2}$ and ourselves ${ }^{3}$ showed that the plasma concentration of noradrenaline increased in patients with congestive heart failure, suggesting that the sympathetic nervous activity of these patients is increased. On the other hand, Eckberg et al found that the parasympathetic influence on sinoatrial node automaticity as determined by vagal blockade with atropine was reduced in patients with heart failure. ${ }^{4}$ They also reported that baroceptor-induced slowing of the heart rate provoked by phenylephrine was appreciably reduced in patients with heart disease. ${ }^{4}$

With cyclic adenosine monophosphate (AMP), which is the second messenger for beta adrenergic agents and many hormones, the plasma concentration appears to reflect the changes in tissue ${ }^{5}$ since the nucleotide in plasma is in a dynamic steady state relation with its intracellular pools. ${ }^{6}$ Cyclic guanosine monophosphate (GMP), like cyclic AMP, is present in plasma, ${ }^{7}$ and its plasma concentration cyclic AMP

Requests for reprints to Dr K Ogawa, 2nd Department of Internal Medicine, Nagoya University School of Medicine, 65 Tsuruma-cho, Showa-ku, Nagoya 466, Japan.

Accepted for publication 26 January 1984 could serve as an index for cholinergic activity. ${ }^{8}$ In the present study, therefore, the plasma concentrations of $\frac{}{\Phi}$ noradrenaline, cyclic AMP, and cyclic GMP were measured simultaneously in patients with congestive heart failure.

\section{Patients and methods}

Eighty five normal subjects ( 54 men and 31 women, mean age 47 years) and 138 patients with congestive 3 . heart failure were studied. The latter group com- $\dot{\delta}$ prised 41 patients with ischaemic heart disease, $40 \gtreqless$ with valvular heart disease, 13 with hypertensive 을 heart disease, 13 with cor pulmonale, 10 with cardiomyopathy, five with myocarditis, five with congen- $\frac{D}{2}$ ital anomalies, 11 with other heart diseases. The patients were classified according to the functional of New York Heart Association classification: $17 \mathrm{~N}$ patients in class 1,37 in class II, 55 in class III, and $29 \mathrm{~N}$ in class IV. The classification was carried out by other 0 doctors who were unaware of the biochemical results. About half the patients with congestive heart failure had been receiving conventional treatment with $\stackrel{\infty}{-}$ digitalis and diuretics $(0.125$ to $0.25 \mathrm{mg}$ of digoxin or 7 $40 \mathrm{mg}$ of frusemide daily respectively or both; $47.0 \%$ in class I, $51.4 \%$ in class II, $56.4 \%$ in class III, and $\stackrel{\odot}{\circ}$ $48.3 \%$ in class IV receiving digoxin). 
PLASMA NORADRENALINE CONCENTRATIONS

For the study of plasma concentrations of noradrenaline, 102 normal subjects and 203 patients with congestive heart failure were studied (NYHA classification: 34 patients in class $I, 51$ patients in class II, 74 patients in class III, and 44 patients in class IV). Plasma concentrations of cyclic nucleotides were also estimated in some of these subjects.

\section{PULMONARY ARTERY PRESSURE}

Cardiac catheterisation was carried out with an intracardiac catheter in the morning after fasting overnight in 33 patients with congestive heart failure. Pulmonary arterial pressure was measured with a Cournand catheter and recorded with a Nihon Koden multipurpose polygraph using a Mingograph 800 recorder and a Statham P23ID pressure transducer. Mean pressure was obtained by electrical integration of the pulse contours. In the patients who did not undergo cardiac catheterisation blood samples were collected in the morning after an overnight fast. The subjects were allowed a 20 min rest period in the supine or Fowler's position and then blood samples were collected. These were collected into a chilled tube packed in ice with $20 \mu \mathrm{l}$ of $0.5 \mathrm{~mol}$ edetic acid and immediately centrifuged at $4^{\circ} \mathrm{C}$. Plasma was separated and frozen at $-20^{\circ} \mathrm{C}$ until assayed. Plasma cyclic nucleotide concentrations were simultaneously measured in duplicate by the radioimmunoassay method of Cailla et $a^{910}$ as modified by Honma et al.11 In this assay, cyclic nucleotides in a $100 \mu \mathrm{l}$ aliquot of plasma were directly succinated without prior deproteinisation and then were bound to the antibody in an imidazole buffer. The assay's total sensitivity increased appreciably by the use of this buffer. This sensitive radioimmunoassay method can be applied to plasma or tissue samples directly without deproteinisation and with minimal dilution. ${ }^{11}$ Total sensitivity was so much enhanced that the concentrations of cyclic AMP and cyclic GMP contained in 0.05 $\mathrm{ml}$ of whole blood could be measured with accuracy, precision, and specificity. The recovery of cyclic AMP was $105(5 \cdot 5) \%$ and that of cyclic GMP 93(2.0)\% when compared with known added cyclic nucleotides.

\section{PLASMA NORADRENALINE CONCENTRATIONS}

The concentration of plasma noradrenaline was measured by a sensitive radioenzymatic method by Henry et $a^{12}$ modified by Lake et al. ${ }^{13}$ In this assay, noradrenaline was $N$-methylated by phenylethanolamine- $N$-methyltransferase, purified from bovine adrenal medulla and ${ }^{3} \mathrm{H}-\mathrm{S}$-adenosyl-1-methionine (New England Nuclear) to form ${ }^{3} \mathrm{H}$-adrenaline, which was selectively isolated and measured by liquid scintillation spectrometry (Beckman LS-335). In this assay, the recovery of noradrenaline from alumina with ace- tic acid was about $40 \%$. Coefficients of variation of intra-assay and interassay of noradrenaline were both within $10 \%$.

\section{STA IISTICS}

A one way analysis of variance was used to determine any significant differences in the group means. If the analysis of variance indicated a significant difference, a two tail, paired or unpaired $t$ test was applied when appropriate. ${ }^{14}$ Probabilities were considered significant at the 0.05 level. Regression lines were fitted by the method of least squares. All values were expressed as mean \pm standard error of mean (SEM).

\section{Results \\ PLASMA CONCENTRATION OF CYCLIC NUCLEOTIDES}

\section{Normal subjects}

Mean plasma concentrations of cyclic AMP and cyclic GMP in 85 normal subjects were $17.5(0.42) \mathrm{nmol} / \mathrm{l}$ and $3.9(0.16) \mathrm{nmol} / \mathrm{l}$ respectively. Figure 1 shows the mean concentration of cyclic AMP in relation to age. The concentration in patients aged between 60 and 69 years was higher and that of those aged between 70 and 79 years lower than that of patients in the other age groups. The mean concentration of cyclic GMP for patients aged 60-90 years was higher and that of those aged $20-29$ years lower than that of patients in the other age groups. There was no significant correlation between the concentration of cyclic AMP and age in normal subjects, but the concentration of cyclic GMP was weakly correlated with age in normal subjects $(r=0.443, p<0.001)$ when those aged between 70 and 79 years were excluded.

\section{Congestive heart failure}

Figure 2 shows the mean plasma concentrations of cyclic AMP and cyclic GMP in patients with congestive heart failure according to the severity (NYHA class) of their symptoms. Cyclic AMP concentrations were significantly higher in patients in class II, III, and IV than in the normal subjects $(p<0.001)$ and in patients in classes III $(p<0.001)$ and IV $(p<0.05)$ than in those in class II. Cyclic GMP concentrations were significantly higher in patients in all classes than in the normal subjects $(p<0.001)$ and in those in classes II $(p<0.05)$, III $(p<0.001)$, and IV $(p<0.005)$ than in those in class $I$; the mean concentration in patients in class III ( $p<0.05)$ was also significantly higher than in those in class II (Fig. 2).

There were no significant effects of conventional treatment with digitalis and diuretic agents on plasma cyclic AMP and cyclic GMP concentrations in patients with the same severity of congestive heart 


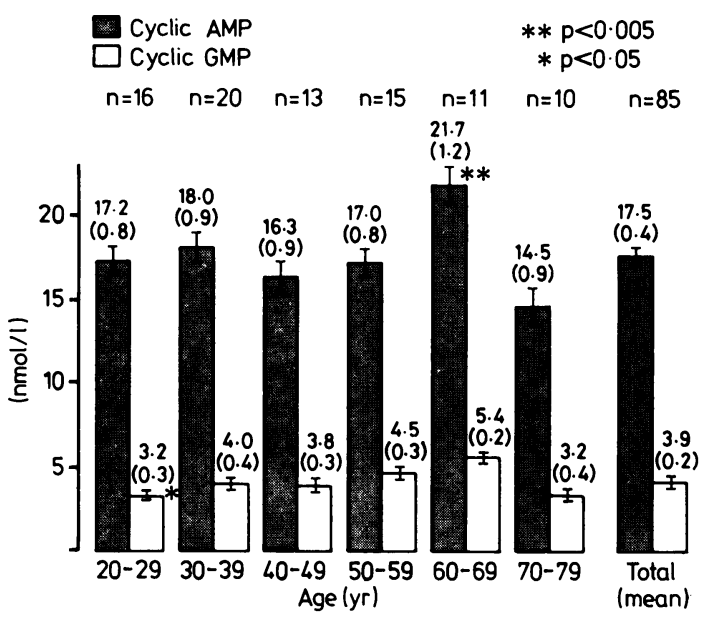

Fig. 1 Mean plasma concentrations of cyclic nucleotides in normal subjects in relation to age. Bars represent SEM.

failure (for example, $24 \cdot 13(3.02) \mathrm{nmol} / \mathrm{l}$ in 12 patients and $11.02(1.90) \mathrm{nmol} / \mathrm{l}$ in nine patients respectively taking $0.25 \mathrm{mg}$ of digoxin and $40 \mathrm{mg}$ of frusemide daily $v 29.74(3.43) \mathrm{nmol} / \mathrm{l}$ in 14 patients and $15.0(2.05) \mathrm{nmol} / \mathrm{l}$ in 12 patients respectively taking no drugs; both groups were in NYHA class IV; both, NS).

\section{CORRELATION BETWEEN MEAN PLASMA}

\section{CONCENTRATION OF NORADRENALINE AND} CYCLIC NUCLEOTIDES

Mean plasma concentrations of noradrenaline were $0.20(0.02) \mu \mathrm{g} / \mathrm{l}$ in the normal subjects, $0.17(0.04) \mu \mathrm{g} / \mathrm{l}$ in the patients in NYHA class I, $0.30(0.03) \mu \mathrm{g} / \mathrm{l}$ in those in NYHA class II, $0.37(0.03) \mu \mathrm{g} / \mathrm{l}$ in those in NYHA class III, and $0.93(0.07) \mu \mathrm{g} / 1$ in those in NYHA class IV. A significant correlation between the mean plasma noradrenaline concentration $(\mathbf{x})$ and mean plasma cyclic AMP concentration ( $y$ ) was found in normal subjects and in patients with congestive heart failure $(y=17.4 x+16.1, r=0.91, p<0.005)$. The correlation between mean plasma noradrenaline concentration ( $\mathbf{x}$ ) and plasma cyclic GMP concentration (y) was, however, not significant $(y=13 \cdot 8 x+4 \cdot 73$, $\mathrm{r}=0.86, \mathrm{p}<0 \cdot 1)$.

\section{CORRELATION BETWEEN MEAN PULMONARY ARTERY PRESSURE AND CYCLIC NUCLEOTIDE CONCENTRATIONS}

Mean pulmonary artery pressure $(x)$ in patients with congestive heart failure was significantly correlated with plasma cyclic AMP concentrations (y) $(y=0.34 x+12.18, r=0.47, p<0.005)$ (Fig. 3a). Similarly, mean pulmonary artery pressure in patients
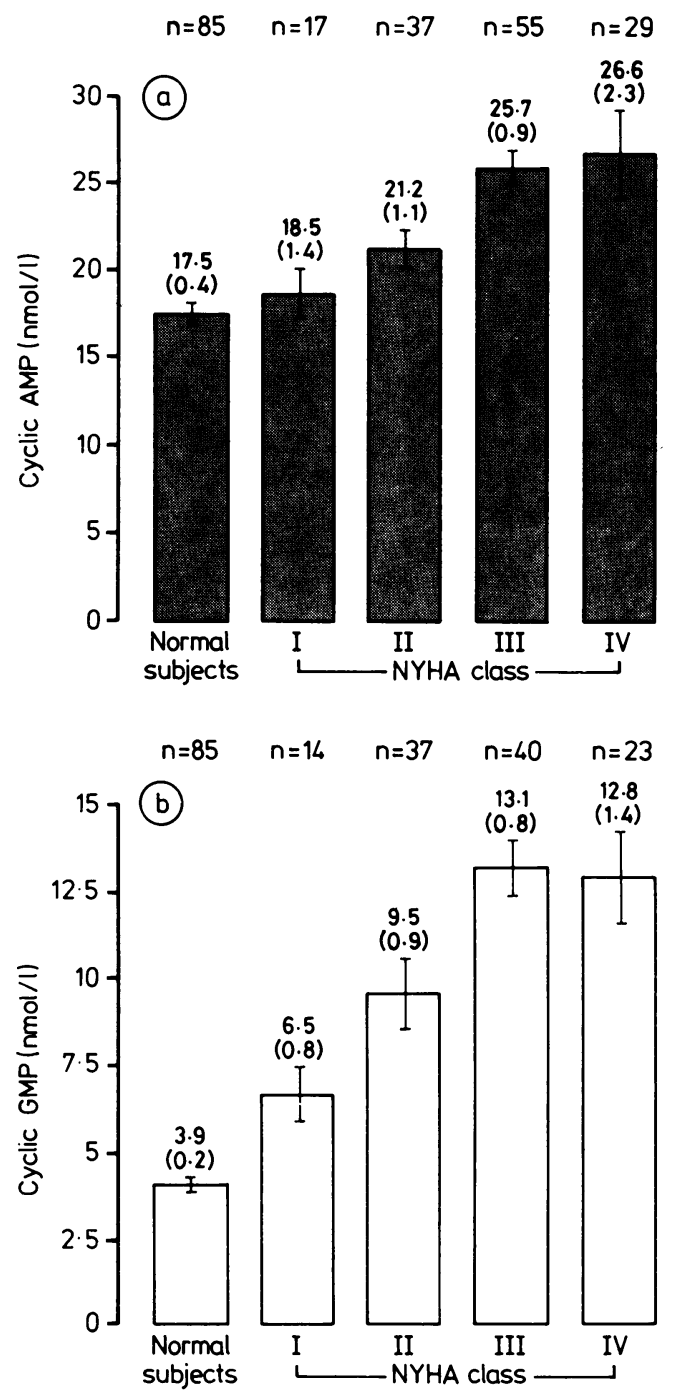

Fig. 2 Mean (SEM) plasma concentrations of (a) cyclic AMP and (b) cyclic GMP according to functional activity by $N Y H A$ functional class. $p$ values: (a) classes $I I, I I I$, and $I V$ v normal subjects, $p<0.001$; class $I I I$ v class $I I, p<0.001$; class $I V \mathrm{v}$ class II, $p<0.05$; (b) all classes v normal subjects, $p<0.001$; class $I I$ v class $I, p<0.05 ;$ class $I I I$ v class $I, p<0.001 ;$ class $I V$ $\mathrm{v}$ class $I, p<0.005 ;$ class III $\mathrm{v}$ class II, $\mathrm{p}<0.05$.

with congestive heart failure was significantly corre- N lated with plasma cyclic GMP concentrations $(y)$ $(y=0.26 x+1.36, r=0.65, p<0.02)($ Fig. 3b).

SERIAL CHANGES OF CYCLIC NUCLEOTIDES AFTER ACUTE LEFT HEART FAILURE

Serial changes of cyclic nucleotides in four patients ${ }^{\circ}$

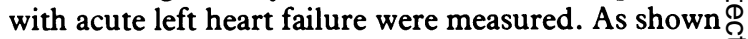
in Fig. 4, the plasma concentrations of cyclic AMP $\mathbb{\otimes}$ 

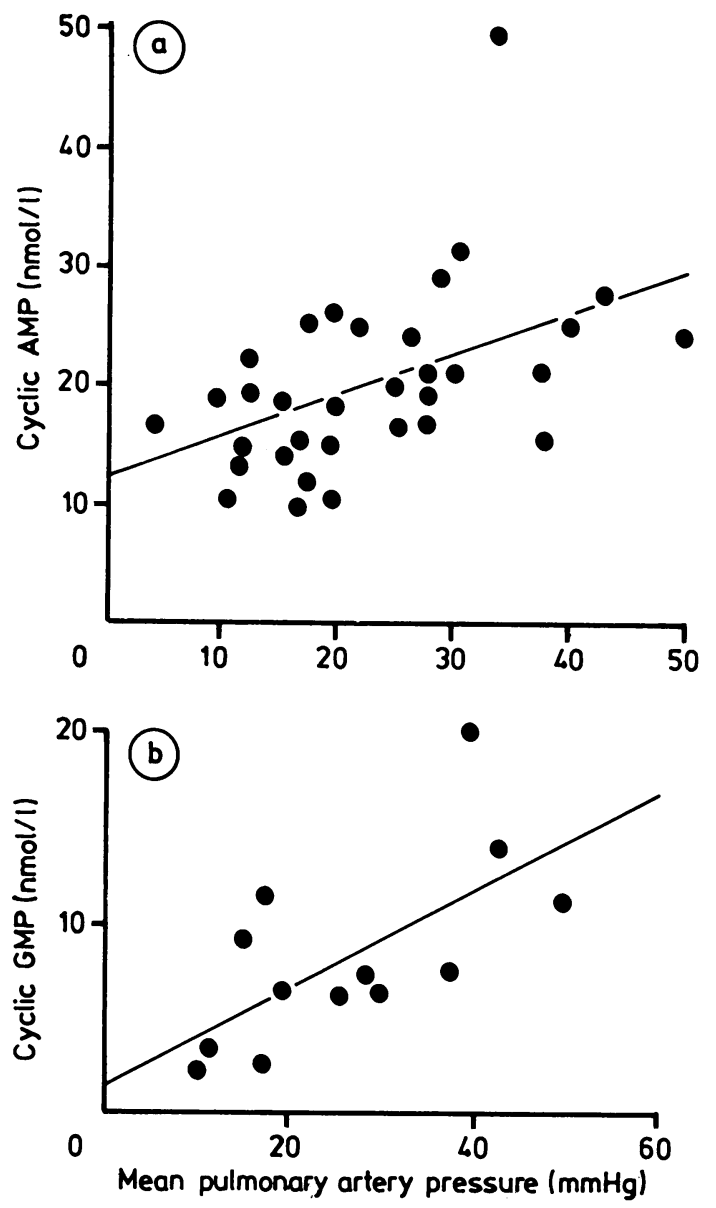

Fig. 3 Correlation between mean pulmonary artery pressure and plasma concentration of (a) cyclic AMP and (b) cyclic $G M P$ in patients with congestive heart failure. $(a)$ $y=0.34 x+12 \cdot 18, r=0.47, p<0.005(n=33) ;(b)$ $y=0 \cdot 26 x+1 \cdot 36, r=0 \cdot 65, p<0 \cdot 02(n=13)$.

and cyclic GMP were $42 \cdot 75(5.31)$ and $35.58(14.0)$ $\mathrm{nmol} / \mathrm{l}$ respectively at the onset of acute left heart failure (NYHA class IV). The plasma concentration of cyclic AMP was appreciably lower at about $20 \mathrm{nmol} / \mathrm{l}$ after the second day of initial improvement (NYHA class III or II) whereas that of cyclic GMP remained at a higher level $(20 \mathrm{nmol} / \mathrm{l})$ than the normal value for more than seven days after the initial improvement.

PLASMA CONCENTRATIONS OF CYCLIC NUCLEOTIDES IN VARIOUS TYPES OF HEART DISEASE

Valvar, ischaemic, and hypertensive heart disease Mean plasma concentration of cyclic AMP in patients

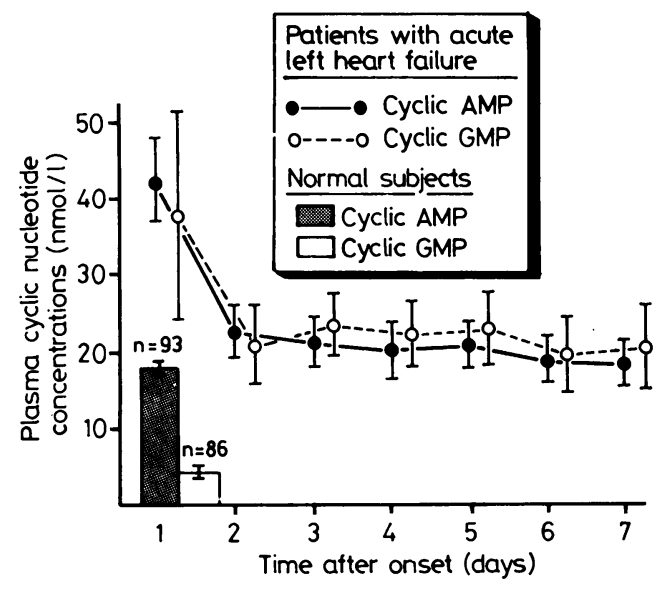

Fig. 4 Serial changes of cyclic nucleotide concentrations after acute left heart failure.

with congestive heart failure due to valvar heart disease was $23.48(1.26) \mathrm{nmol} / \mathrm{l}$ compared with $23.25(1.25) \mathrm{nmol} / \mathrm{l}$ in those in whom it was due to ischaemic heart disease and 24.03(1.93) nmol/ 1 in patients in whom it was due to hypertensive heart disease. These findings were significantly higher than those in normal subjects $(\mathrm{p}<0.001)$, but there was no significant difference among patient groups with con-
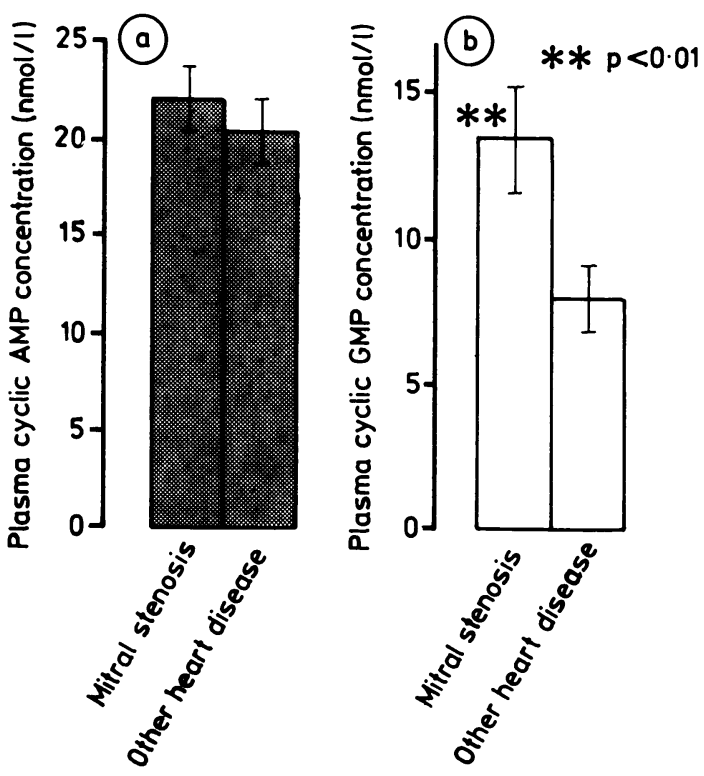

Fig. 5 Comparison of mean plasma concentrations of cyclic nucleotides in patients with mitral stenosis $(n=16)$ and other heart disease $(n=21)$ (NYHA class $I I)$. 
gestive heart failure due to each type of heart disease.

The mean plasma concentration of cyclic GMP in patients with congestive heart failure due to valvar heart disease was $10.78(0.80) \mathrm{nmol} / \mathrm{l}$ compared with $10.99(1.05) \mathrm{nmol} / \mathrm{l}$ in those in whom it was due to ischaemic heart disease and $10.49(1.37) \mathrm{nmol} / \mathrm{l}$ in those in whom it was due to hypertensive heart disease. These findings were significantly higher than those in normal subjects, but there was no significant difference among patient groups with congestive heart failure due to each type of heart disease. There was also no significant difference among the other patient groups with congestive heart failure.

\section{Mitral stenosis}

The mean concentration of cyclic GMP in patients with congestive heart failure in class II due to mitral stenosis was $13.35(1.78) \mathrm{nmol} / \mathrm{l}$, which was significantly higher $(\mathbf{p}<0.01)$ than that in patients with other types of heart disease $(7.87(1.09) \mathrm{nmol} / \mathrm{l}$. The mean plasma concentration of cyclic AMP in patients with congestive heart failure in the same class of mitral stenosis was, however, $22.13(1.56) \mathrm{nmol} / \mathrm{l}$, whereas that of the other heart diseases was 20.29(1.62) nmol/1 (NS) (Fig. 5).

\section{Discussion}

Recent studies have shown that the plasma concentration of cylic AMP and cyclic GMP in experimental animals and human subjects increased sharply on the administration of hormones or neurotransmitters, reflecting increases in the intracellular cyclic nucleotides caused by each cyclase activation. ${ }^{1516}$ Tyramine causes the discharge of catecholamines from adrenergic neuronal terminals, and its injection into rats leads to a rapid but short lived increase in plasma concentrations of cyclic AMP. ${ }^{17}$ Injection of cholinergic agents caused sharp increases in plasma cyclic GMP in fasted rats. ${ }^{8} \mathrm{Ui}$ et al reported that vigorous exercise significantly increased plasma cyclic AMP and cyclic GMP. ${ }^{15}$ The increase in plasma cyclic AMP was abolished by propranolol and reduced by atropine, whereas the increase in plasma cyclic GMP was not affected by propranol but was abolished by atropine, which suggests that muscarinic receptors are involved. Adrenaline produced significant increases in plasma cyclic AMP that were associated with slight increases in plasma cyclic GMP. ${ }^{18}$ Injection of insulin into healthy human subjects increases the plasma concentration of cyclic AMP, but there is little, if any, increase in plasma cyclic GMP after insulin injection. ${ }^{19-21}$ It is well known that the administration of insulin induces hypoglycaemia and an increased secretion of adrenaline from the adrenal medulla. Hypotension elicited by methacholine resulted in a significant increase in plasma cyclic GMP associated with slight increases in plasma cyclic AMP. ${ }^{\circ} \stackrel{.}{.}$ Although there is evidence that increased sympathetic $\underset{\overrightarrow{0}}{\vec{*}}$ activity increases plasma cyclic AMP and increased $\overrightarrow{0}$ parasympathetic activity increases plasma cyclic $\frac{\bar{\sigma}}{\sigma}$ GMP, factors other than autonomic activity affect tis- $\frac{\bar{c}}{\bar{D}}$. sue concentrations of cyclic AMP and GMP. A variety $\frac{\mathbb{Q}}{2}$ of polypeptide hormones other than insulin affects the concentrations of cyclic AMP in certain tissues, and ${ }^{\infty}$ non-hormonal factors such as acid base status ${ }^{22}$ and $\vec{\circ}$ prostaglandins $^{23}$ also have some effect. Similarly, tis- $\vec{\omega}$ sue concentrations of cyclic GMP are known to be $\stackrel{\sigma}{\sigma}$ affected by prostaglandins, ${ }^{24}$ acid base changes, ${ }^{25} \bar{\jmath}$ potassium, ${ }^{26}$ and angiotensin. ${ }^{16}$ These factors, how- if ever, seemed to have little influence on the plasma of concentration of the cyclic nucleotides in patients in of this study since the plasma noradrenaline concentrations were significantly correlated with cyclic AMP 은 concentrations in patients with congestive heart fail- ure.

After acute myocardial infarction, the plasma cyclic AMP concentration in patients without complications $\frac{1}{3}$ was significantly increased on the first day. ${ }^{27} 28$ The $\underset{\mathbb{D}}{\overparen{D}}$ concentration in patients with complications was also $\overrightarrow{\vec{P}}$ significantly higher than in those without. ${ }^{28}$ On the $\mathscr{\odot}$ other hand, there was an increase in plasma cyclic ${ }^{+}$ GMP concentration, which remained raised until the eighth day after acute myocardial infarction. ${ }^{28}$

In patients with essential hypertension, the plasma concentration of cyclic AMP was significantly higher $\stackrel{2}{\circ}$ in untreated patients, those treated with a diuretic $\stackrel{\mathbb{Q}}{\square}$ agent, and those treated with propranolol than in $\overrightarrow{\overrightarrow{0}}$ normal subjects, but the plasma concentration of $\frac{0}{3}$ cyclic GMP was similar in normal subjects and untreated patients. ${ }^{29} 30$ Plasma cyclic AMP concentrations? decreased significantly, whereas those of cyclic GMP increased significantly after long term treatment with propranolol. ${ }^{29}$

In the present study the increased concentration of cyclic nucleotides in patients with congestive heart 8 failure is unlikely to have been due to the diminished $\frac{3}{3}$ urine output in these patients, since the half life of $\mathrm{O}$ ${ }^{3} \mathrm{H}$-labelled cyclic GMP and cyclic AMP in human whole blood in vitro at $37^{\circ} \mathrm{C}$ is $30-50$ minutes ${ }^{6}$ and $\frac{D}{3}$ renal excretion accounts for only about $15 \%$ of the clearance of each of these nucleotides in man. ${ }^{6}$ It is $\mathcal{N}$ interesting that the plasma concentration of cyclic N GMP increased in patients with mitral stenosis, plac- N ing a heavy burden on the left atrium. Stimulation of ${ }_{\sigma}^{\omega}$ the dense parasympathetic nerves in the atrium may have been responsible for the increased plasma con- $\frac{-}{D}$ centration of cyclic GMP in these patients. In our study, there was no significant effect of conventional ${ }_{T}$ treatment with digitalis and diuretic agents on the cyclic nucleotide concentrations in patients with con- $\overrightarrow{\mathbb{D}}$ gestive heart failure of the same severity. The reason $\frac{?}{\mathbb{Q}}$ 
for this may be that the plasma concentration of cyclic nucleotides in patients with congestive heart failure increases with the symptomatic severity of heart failure as well as with the increase in pulmonary artery pressure, which is an index of congestive heart failure.

In conclusion, the present findings show that plasma concentrations of cyclic AMP and cyclic GMP were significantly increased in patients with congestive heart failure. Mean pulmonary artery pressure was significantly correlated with plasma cyclic AMP as well as cyclic GMP concentrations in these patients. Furthermore, the plasma cyclic GMP concentration in patients with mitral stenosis was significantly increased compared with that in other types of heart failure.

Part of this work has been presented at the 8th European Congress of Cardiology in Paris and was supported in part by a grant-in-aid for scientific research from the Ministry of Education, Science, and Culture of Japan.

\section{References}

1 Chidsey CA, Braunwald E, Morrow AG. Catecholamine excretion and cardiac stores of norepinephrine in congestive heart failure. Am $\mathcal{F}$ Med 1965;39:442-51.

2 Thomas JA, Marks BH. Plasma norepinephrine in congestive heart failure. Am $\mathcal{f}$ Cardiol 1978;41:233-43.

3 Ban M, Ogawa K, Satake T. Plasma norepinephrine in congestive heart failure and acute myocardial infarction. Fapanese Fournal of Medicine 1979;19:76.

4 Eckberg DL, Drabinsky M, Braunwald E. Defective cardiac parasympathetic control in patients with heart disease. $N$ Engl f Med 1971;285:877-83.

5 Strange RC, Mjos OD. The sources of plasma cyclic AMP: studies in the rat using isoprenaline, nicotinic acid and glucagon. Eur $\mathcal{F}$ Clin Invest 1975;5:147-52.

6 Broadus AE, Kaminsky NI, Hardman JG, Sutherland EW, Liddle GW. Kinetic parameters and renal clearances of plasma adenosine $3^{\prime}, 5^{\prime}$ monophosphate and guanosine 3', 5'-monophosphate in man. $\mathcal{F}$ Clin Invest 1970;49:2222-45.

7 Hardman JG, Davis JW, Sutherland EW. Effects of some hormonal and other factors on the excretion of cyclic guanosine $3^{\prime}, 5^{\prime}$ monophosphate and adenosine $3^{\prime}, 5^{\prime}$ monophosphate in rat urine. $f$ Biol Chem 1969;244:6354-62.

8 Honma $M$, Ui $M$. Plasma cyclic GMP: response to cholinergic agents. Eur f Pharmacol 1978;47:1-10.

9 Cailla HL, Racine-Weisbuch MS, Delaage MA. Adenosine $3^{\prime}, 5^{\prime}$-cyclic monophosphate assay at $10^{-15}$ mole level. Anal Biochem 1973;56:394-407.

10 Cailla HL, Vannier CJ, Delaage MA. Guanosine 3',5'cyclic monophosphate assay at $10^{\left.-15^{-}\right)}$mole level. Anal Biochem 1976;70:195-202.

11 Honma H, Satoh T, Takezawa J, Ui M. An ultrasensitive method for the simultaneous determination of cyclic AMP and cyclic GMP in small-volume samples from blood and tissue. Biochem Med 1977;18:257-73.

12 Henry DP, Starman BJ, Johnson DG, Williamas RH. A sensitive radioenzymatic assay for norepinephrine in tissues and plasma. Life Sci 1975;16:375-84.

13 Lake CR, Ziegler MG, Kopin IJ. Use of plasma norepinephrine for evaluation of sympathetic neural function in man. Life Sci 1976;18:1315-26.

14 Wallenstein S, Zucker CL, Fleiss JL. Some statistical methods useful in circulation research. Circ Res 1980;47:1-9.

15 Ui M, Honma M, Kunitada S et al. Adrenergic and cholinergic modulation of extracellular cyclic nucleotides. Adv Cyclic Nucleotide Res 1980;12:25-35.

16 Rosman PM, Agrawal R, Goodman AD, Steiner AL. Effect of angiotensin II on cyclic guanosine monophosphate and cyclic adenosine monophosphate in human plasma. F Clin Endocrinol Metab 1976;42:531-6.

17 Kunitada S, Honma M, Ui M. Increases in plasma cyclic AMP dependent on endogenous catecholamines. Eur $\mathcal{F}$ Pharmacol 1978;48:159-69.

18 Ball JH, Kaminsky NI, Hardman JG, Broadus AE, Sutherland EW, Liddle GW. Effects of catecholamines and adrenergic-blocking agents on plasma and urinary cyclic nucleotides in man. $\mathcal{F}$ Clin Invest 1972;51:2124-9.

19 Brodows RG, Ensinck JW, Campbell RG. Mechanism of plasma cyclic AMP response to hypoglycemia in man. Metabolism 1976;25:659-63.

20 Hamet P, Lowder SC, Hardman JG, Liddle GW. Effect of hypoglycemia on extracellular levels of cyclic AMP in man. Metabolism 1975;24:1139-44.

21 Siddle K, Davies CJ, Shetty KJ, Elkeles RS. The effect of insulin on adenosine $3^{\prime}: 5^{\prime}$ monophosphate and guanosine $3^{\prime}: 5^{\prime}$ monophosphate concentrations in human plasma. Clin Sci Mol Med 1976;50:487-91.

22 Beck N, Kim HP, Kim KS. Effect of metabolic acidosis on renal action of parathyroid hormone. Am $\mathcal{F}$ Physiol 1975;228:1483-8.

23 Beck NP, Kaneko T, Zor U, Field JB, Davis BB. Effects of vasopressin and prostaglandin $E_{1}$ on the adenyl cyclase-cyclic 3',5'-adenosine monophosphate system of the renal medulla of the rat. $\mathcal{F}$ Clin Invest 1971;50: 2461-5.

24 Dunham EW, Haddox MK, Goldberg ND. Alteration of vein cyclic $3^{\prime}, 5^{\prime}$ nucleotides concentrations during changes in contractility. Proc Natl Acad Sci USA 1974;71:815-9.

25 Goodman AD, Steiner AL, Pagliara AS. Effects of acidosis and alkalosis on $3^{\prime}, 5^{\prime}-$ GMP and $3^{\prime}, 5^{\prime}$-AMP in renal cortex. Am $\mathcal{f}$ Physiol 1972;223:620-5.

26 Goldberg ND, O’Dea RF, Haddox MK. Cyclic GMP. Adv Cyclic Nucleotide Res 1973; 3: 155-223.

27 Rabinowitz B, Kligerman M, Parmley WW. Plasma cyclic adenosine $3^{\prime}, 5^{\prime}$-monophosphate (AMP) levels in acute myocardial infarction. Am $\mathcal{f}$ Cardiol 1974; 34: 7-11.

28 Kondo T, Ogawa K, Ban M, Ogasaware B, Watanabe E, Satake T. Plasma level of norepinephrine and cyclic nucleotides following acute myocardial infarction. $\mathcal{~ p n ~ H e a r t ~}$ f 1981; 22: 593-603.

29 Tsuchiya S, Ogawa K, Satake T. Plasma levels of cyclic nucleotides in patients with essential hypertension. $\mathcal{F}$ n Heart $\mathcal{F}$ 1980; 21: 803-15.

30 Ogawa K, Matsuno T, Tsuchiya S, Ban M, Minaguchi K. Plasma level of norepinephrine, cyclic AMP and cyclic GMP in essential hypertension. F pn Circ $\mathcal{F}$ 1981; 45: 654-60. 